ISSN: 1991-0037

SOUTH ASIAN JOURNAL OF AGRICULTURE

An Open Access Peer Reviewed Journal

South Asian J. Agric.

Research Article

Vol. 7, No. 1\&2, 2016-'19: 44-50

\title{
Identification of Training Needs for Teachers of Khulna University of Bangladesh
}

\author{
Author: Mohammad Bashir Ahmed* and Md. Abdul Mannan \\ Professor, Agrotechnology Discipline, Khulna University, Khulna-9208, Bangladesh \\ *Corresponding author: Mohammad Bashir Ahmed; E-mail: mbaat_ku@yahoo.com
}

ABSTRACT

\author{
Received: \\ 13 January, 2019 \\ Accepted: \\ 28 January, 2019 \\ Online: \\ 31 March, 2019 \\ Key words: \\ Identification, Training \\ needs, University \\ teachers
}

\begin{abstract}
The main purpose of the study was to identify the training needs of the teachers of Khulna University. Data were collected from randomly selected 54 teachers out of 280 through mailed questionnaire (Both hard and email copy) during June to July, 2010. To identify level of knowledge and training needs of the respondents 20 items/ issues under 5 broad areas (viz. teaching methodology, research methodology, computer skill, office management $\&$ administration and extension \& outreach) were selected. To determine the level of knowledge a 5- points rating scale such as little knowledge, some knowledge, substantial knowledge, high knowledge and very high knowledge were used and a score of 1,2,3, 4 and 5 were assigned against the scales respectively. To determine the training need a 5- points rating scale such as little need, some need, substantial need, urgent need and very urgent need were employed and a score of 1, 2, 3, 4 and 5 were assigned against the scales respectively. To identify the issues and areas of knowledge and training, knowledge index and training need index were calculated respectively. The respondents had highest level of knowledge in teaching methodology, while it was least in case of extension and outreach among the five selected broad categories. The respondents expressed very urgent training needs in extension and outreach and least training needs in teaching methodology. The respondent teachers also identified top five issues on which they want to take training are conflict management (under extension and outreach), budget preparation (office management and administration) acquaintance with field problem (extension and outreach), research design and project preparation (research methodology), and data analysis and management (computer skill). Among age, professional experience, educational qualification training experience and level of knowledge, only level of knowledge showed a negative significant relationship with the training need of the respondents.
\end{abstract}

To cite this article: Ahmed, M.B. and Mannan, M.A. 2019. Identification of Training Needs of Teachers of Khulna University of Bangladesh., South Asian J. Agric., 7(1\&2): 44-50.

\section{INTRODUCTION}

Khulna University is one of the renowned public universities established in 1987 and started its academic program in 1991. After emergence as public university in the educational arena/sector of Bangladesh, at first stage it offers education in 4-specialised disciplines viz. Architecture, Business Administration, Computer Science and Engineering and Urban and Rural Planning under two schools (such as Science Engineering and Technology (SET) and Management and Business Administration schools. Subsequently it extends its horizon to five schools consisting of 16-disciplines \{ such as Agrotechnology (AT), Biotechnology and Genetic Engineering (BGE), Environmental Science (ES), Fisheries and Marine Resources Technology (FMRT), Forestry and Wood Technology (FWT), Pharmacy and Soil science (SS) Disciplines under Life Science (LS) School, Architecture, Computer Science and Engineering (CSE), Electronic and Communication Engineering (ECE), Mathematics and Urban and Rural Planning (URP) Disciplines under Science Engineering and Technology (SET) School, Business Administration under Management and Business Administration (MBA) School, Economics and Sociology under Social Science (SS) School and English under Arts and Humanities (AH) School\}. On the occasion of two decades of its establishment, Khulna University authority has passed its first organogram up to 2017. The organogram covered 45- disciplines under 7-schools (two new schools viz. Education and Law school), 6-institutes and 5-centres. But in fiscal year 2009-10, the organogram was revised. The revised organogram covered 32-disciplines under 7-schools, 3institutes and 2-centres (from 2008-09 to 2018-19). Every discipline offers undergraduate program and most of the disciplines offer postgraduate program(s). Each of the undergraduate students of all disciplines needs to submit a project thesis as a core course under the supervision of a teacher of the respective discipline. The teaching strength during the study period was 280 (presently 340) and the proposed teaching strength in the first organogram was 1364 projected to 2017. But in revised organogram the number of the teachers is 821 up to $2018-19$. After joining, the teachers of the university have no opportunity to train themselves in any area or issue of academic, research and administrative and financial management concern. Only in their own initiative, they pursue higher academic degree to enrich themselves. Without knowledge in research methodology, teaching methodology, office management, computer skill and outreach activity, an individual can not be an ideal and perfect teacher. Besides, no induction or foundation training is offered to the newly recruited teachers of the university as it is offered to the newly recruited BCS cadre officers and officers in other public services. Consequently, specially the young teachers face a lot of problems in expert teaching, conducting 
research and technical report writing, office and financial management etc. (as they have to perform some administrative and financial activities in addition to teaching and research). The University Grants Commission (UGC) of Bangladesh has taken initiative to train up the teachers of public universities from February 2008. As a part of these training 25 teachers of different public universities including $\mathrm{KU}$ have received training from Graduate Training Institute (GTI), Bangladesh Agricultural University (BAU), Mymensingh. But UGC has not taken any initiative to identify the needs of the teachers (trainees). Besides, the teachers are not so interested to participate in the training program venued at other than their own university. To perform efficient and effective services (for career development) training is an urgent and most important factor.

Training is the process of improving knowledge and skill and of changing attitude for doing specific job properly. Van Darsal (1962) defined training as a process of teaching, informing or educating people so that

- They may become as well qualified as possible to do their job and

- They become qualified to perform in position of greater difficulty and responsibility.

Jucions (1963) defined training as a process of acquiring specific skills to perform a job in a better way.

Training is broadly categorized into two types

i. Pre-service training, and

ii. In-service training

In-service training is a process of staff development for the purpose of improving the performances of an incumbent holding a position, with assigned job responsibilities. Among several in-service trainings, the induction/foundation and career development trainings are the most important ones. The induction training is offered immediately after employment to introduce the newly staff members to their position (Rogers and Olmsted, 1957). On the other hand career development training is the act of acquiring information and resources that enable one to plan a program of life-long learning related to his/her work life (Malone, 1984).

To design / develop training curriculum and module for the teachers' it is essential to identify their needs including areas of training. The training need identification assists the trainers to plan a training program considering the areas needed to be focused. Training need identification is possible through different analytical procedures viz. organizational analysis, individual analysis and group analysis. The present study has focused on individual analysis.

\section{Objectives of the study}

Considering these issues in view, the current study was undertaken with the following objectives:

1. To analyze some selected characteristics of the respondents

2. To determine the level of existing knowledge and nature of training needs of the respondents
3. To identify the issues and broad areas of knowledge and training needs and

4. To determine the relationship between selected characteristics of the respondents and their training needs.

\section{METHODOLOGY}

Locale of the study: The study was conducted in Khulna university, Khulna.

Population and sampling design: All the teachers (employed up to 2008) of the Khulna University were treated as the population of the study. A list of teachers (tier wise) was prepared with the help of the Registrar's office of the university. About twenty percent of the teachers (54 out of 280) were selected at random to constitute the sample of the study. Tier wise ratio of the respondent teachers was as Lecture: Assistant Professor: Associate Professor: Professor $=2.5: 3: 1: 1$.

Data collection: Data were collected from sampled teachers to identify their training needs i.e. areas of training required. Besides, data were collected on their personal and socioeconomic profiles (some selected characteristics of the respondents). Data were collected through mailed questionnaire (including emailing). Data collection took two months (JuneJuly, 2010).

Determining the level of knowledge: Level of knowledge of the respondents was determined based on knowledge score. A 20 items/ issues under 5 broad areas (viz. teaching methodology, research methodology, computer skill, office management \& administration and extension $\&$ outreach) were selected to identify the level of knowledge of the teachers. To determine level of knowledge a 5-points rating scale such as little knowledge, some knowledge, substantial knowledge, high knowledge and very high knowledge were used and a score of $1,2,3,4$ and 5 were assigned against the scales respectively.

Each of the respondents was requested to indicate their level of knowledge on the 20 items, under 5 broad areas. The level of knowledge scores of the respondents was determined by adding all the scores against each of the 20 items/ issues. The Level of Knowledge Score (LKS) could range from 20-100, where 20 indicate little knowledge and 100 indicate very high knowledge.

Besides, the important items/ issues as well as the broad areas of knowledge were also identified based on Knowledge Index (KI), which was calculated using the following formula:

Knowledge Index $(\mathrm{KI})=\mathrm{N}_{1} \mathrm{x} 5+\mathrm{N}_{2} \mathrm{x} 4+\mathrm{N}_{3} \mathrm{x} 3+\mathrm{N}_{4} \mathrm{x} 2+\mathrm{N}_{5} \mathrm{x} 1$

Where,

$\mathrm{KI}=$ Knowledge Index

$\mathrm{N}_{1}=$ Number of teachers rated as very high knowledge

$\mathrm{N}_{2}=$ Number. of teachers rated as high knowledge

$\mathrm{N}_{3}=$ Number of teachers rated as substantial knowledge

$\mathrm{N}_{4}=$ Number of teachers rated as some knowledge

$\mathrm{N}_{5}=$ Number of teachers rated as little knowledge 
Table 1. Distribution of the respondents according to schools and disciplines**

\begin{tabular}{|c|c|c|c|c|c|c|}
\hline School & Discipline & Professor & $\begin{array}{l}\text { Associate } \\
\text { Professor }\end{array}$ & $\begin{array}{l}\text { Assistant } \\
\text { Professor }\end{array}$ & Lecturer & Total \\
\hline & AT & 3 & & 2 & 1 & 6 \\
\hline \multirow[t]{6}{*}{ LS } & BGE & 1 & 2 & 5 & & 8 \\
\hline & ES & 1 & 1 & 1 & 1 & 4 \\
\hline & FMRT & 2 & & 4 & 1 & 7 \\
\hline & FWT & & 3 & 1 & 1 & 5 \\
\hline & PHARMACY & & & 2 & & \\
\hline & SS (SWE)* & & & & & $\overline{0}$ \\
\hline \multirow[t]{7}{*}{$\overline{\text { SET }}$} & Architecture & & 1 & & & 1 \\
\hline & CSE & & & 1 & 2 & 3 \\
\hline & Chemistry & & & & & 0 \\
\hline & ECE & & & 3 & 3 & 6 \\
\hline & Mathematics & & & & 2 & 2 \\
\hline & Physics & & & & & 0 \\
\hline & URP & & & & 2 & 2 \\
\hline \multirow[t]{2}{*}{ Soc. SC. } & Economics & & & 1 & & 1 \\
\hline & Sociology & & 1 & 2 & 1 & 0 \\
\hline $\mathrm{AH}^{*}$ & English* & & & & 1 & 1 \\
\hline$\overline{M B A}$ & $\mathrm{BA}$ & & & & 2 & 2 \\
\hline IFA* & IFA* & & & & & \\
\hline Total & & 7 & 8 & 22 & 17 & 54 \\
\hline
\end{tabular}

*IFA= Institute of Fine Arts

*The teachers of those disciplines did not respond regarding this study.

** Presently 18 disciplines and one institute are running. During this study Chemistry and Physics disciplines were under FMRT and Physics disciplines respectively i.e. why these disciplines were not included separately in the sample.

Identification of training needs: Training need was determined based on training need score. A 20 items/ issues under 5 broad areas (viz. teaching methodology, research methodology, computer skill, office management \& administration and extension \& outreach) were selected to do identify the training needs of the teachers. To determine the training need a 5- points rating scale such as little need, some need, substantial need, urgent need and very urgent need were employed and a score of 1, 2, 3, 4 and 5 were assigned against the scales respectively. Each of the respondents was requested to indicate the urgency of the training need on the 20 items under 5 broad areas. The training need scores of the respondents were determined by adding all the scores against each of the 20 items. The Training Need Scores (TNS) could range from 20 to 100 , where 20 indicate little training need and 100 indicates very urgent training need.

Besides, the important items/ issues as well as the broad areas of training were also identified based on training need index (TNI), which was calculated using the following formula:

Training Need Index $(\mathrm{TNI})=\mathrm{N}_{1} \times 5+\mathrm{N}_{2} \times 4+\mathrm{N}_{3} \times 3+\mathrm{N}_{4} \times 2+\mathrm{N}_{5} \times 1$

Where, $\mathrm{TNI}=$ Training Need Index

$\mathrm{N}_{1}=$ Number of teachers rated as very urgent need of training

$\mathrm{N}_{2}=$ Number of teachers rated as urgent need of training

$\mathrm{N}_{3}=$ Number of teachers rated as substantial need of training

$\mathrm{N}_{4}=$ Number of teachers rated as some need of training

$\mathrm{N}_{5}=$ Number of teachers rated as little need of training

Statistical analysis: After collection, data were analyzed by using statistical treatments like number, frequency, percent, mean, standard deviation, rank order etc. for interpretation of the results. To test the relationship between the selected characteristics of the respondents (teachers) and their training need correlation coefficient (r) was estimated.

\section{RESULTS AND DISCUSSION}

Findings of the study have been presented and discussed under the following sections according to the objectives: (1) characteristics of the respondents, (2) level of their existing knowledge and nature of training needs, (3) identification of issues and broad areas of knowledge and training, and (4) relationships between the selected characteristics of the teachers and their training needs.

\section{Characteristics of the Respondents}

Behavior of an individual is largely influenced by his/her characteristics. The characteristics considered in this study were age, present position in Khulna University, professional/service experience, educational qualification and training experience.

\section{Age}

The age of the teachers under study ranged from 25 to 57 years, the average being 33.89 years with a standard deviation of 6.59 . Based on the observed age, the respondents were classified into three categories as it appears in Table 2. Data furnished in the Table 2 reveal that majority $(65 \%)$ of the teachers were middle aged compared to young $(26 \%)$ and the rest $(9 \%)$ were old aged.

Present position in Khulna University (KU)

Considering the present position in Khulna University, the respondents were classified into four categories as shown in Table 3. 
Table 2. Distribution of the respondents according to their age

\begin{tabular}{|c|c|c|c|c|c|}
\hline \multirow[t]{2}{*}{ Categories } & \multirow[t]{2}{*}{ Score (years) } & \multicolumn{2}{|c|}{ Respondents $(\mathrm{N}=54)$} & \multirow[t]{2}{*}{ Mean } & \multirow[t]{2}{*}{ Standard deviation } \\
\hline & & Number & Percentage & & \\
\hline Young aged & Upto 30 & 14 & 26 & 33.88 & 6.59 \\
\hline Middle aged & $31-45$ & 35 & 65 & & \\
\hline Old aged & Above 45 & 5 & 9 & & \\
\hline Total & & 54 & 100 & Min. 25 & Max. 57 \\
\hline
\end{tabular}

Table 3. Distribution of the respondents according to their present position in KU

\begin{tabular}{|c|c|c|c|}
\hline \multirow[t]{2}{*}{ Categories } & \multirow[t]{2}{*}{ Code } & \multicolumn{2}{|l|}{ Respondents $(\mathrm{N}=54)$} \\
\hline & & Number & Percentage \\
\hline Lecturer & 1 & 17 & 31 \\
\hline Assistant Professor & 2 & 22 & 41 \\
\hline Associate Professor & 3 & 8 & 15 \\
\hline Professor & 4 & 7 & 13 \\
\hline Total & & 54 & 100 \\
\hline
\end{tabular}

Table 4. Distribution of the respondents according to their professional/ service experience

\begin{tabular}{lccccc}
\hline Categories & Score (years) & \multicolumn{2}{l}{ Respondents (N=54) } & Mean & Standard deviation \\
\cline { 3 - 6 } & & Number & Percentage & 8.39 & 6.29 \\
\hline Low experience & Up to 5 & 23 & 43 & 33 & \\
\hline Moderate experience & $6-10$ & 18 & & & \\
\hline High experience & Above 10 & 13 & & & \\
\hline Total & & & & & \\
\hline
\end{tabular}

Table 5. Distribution of the respondents according to their level of education

\begin{tabular}{lllllll}
\hline \multirow{2}{*}{ Position held } & \multicolumn{3}{c}{ Respondents (N=54)* } & \multicolumn{2}{c}{ Total } \\
\cline { 2 - 6 } & Post. Doc. & PhD & Double Masters & Masters & $\begin{array}{l}\text { Bachelor } \\
\text { only }\end{array}$ \\
\hline Professor & $1(14.29)$ & $5(71.42)$ & - & $1(14.29)$ & - & $07(100)$ \\
\hline Associate Professor & $1(12.50)$ & $4(50.00)$ & $1(12.50)$ & $2(25.00)$ & - & $08(100)$ \\
\hline Assistant Professor & - & $4(18.18)$ & $2(09.09)$ & $13(59.09)$ & $3((13.64)$ & $22(100)$ \\
\hline Lecturer & - & $1(05.88)$ & - & $9(52.94)$ & $7(41.18)$ & $17(100)$ \\
\hline Total & $2(03.70)$ & $14(25.92)$ & $3(05.56)$ & $25(46.30)$ & $10(18.52)$ & $54(100)$ \\
& & & & & & \\
\hline *Figure in the parenthesis indicates percent of the respondents
\end{tabular}

Table 6. Distribution of the respondents according to their training experience

\begin{tabular}{|c|c|c|c|c|c|}
\hline \multirow[b]{2}{*}{ Categories } & \multirow{2}{*}{$\begin{array}{l}\text { Score } \\
\text { (days) }\end{array}$} & \multicolumn{2}{|c|}{ Respondents (N=54) } & \multirow[b]{2}{*}{ Mean } & \multirow{2}{*}{$\begin{array}{l}\text { Standard } \\
\text { deviation }\end{array}$} \\
\hline & & Number & Percentage & & \\
\hline No training experience & 0 & 08 & 15 & 2.94 & 2.17 \\
\hline Low training experience & $1-3$ & 26 & 48 & & \\
\hline Medium training experience & $4-6$ & 15 & 28 & & \\
\hline High training experience & $>6$ & 09 & 09 & & \\
\hline Total & & 54 & 100 & Min. 0 & Max. 8 \\
\hline
\end{tabular}


Data presented in Table 3 demonstrate that the highest proportion $(41 \%)$ of the teachers were Assistant Professor followed by Lecturer (31\%). The rest $28 \%$ were Professor and Associate Professor. As majority of the disciplines were newly established, so the number of Lecturer and Assistant Professors were higher than that of Associate Professor and Professor.

\section{Professional/ service experience}

A remarkable variation (1-29 years) was found in professional/ service experience of the respondents having an average and standard deviation of 8.39 years and 6.29 respectively. On the basis of professional/ service experience, the respondents were classified into three categories as shown in Table 4.

Data presented in Table 4 reveal that highest proportion (43\%) of the respondents had low experience followed by medium experience (33\%). Around one-fourths (24\%) of the respondents had high professional/ service experience. Thus more than three-fourths $(76 \%)$ of the respondents had low to medium professional/ service experience.

\section{Educational qualification}

Among 54 respondents highest proportion (46.3\%) had MS degree followed by $\mathrm{PhD}(25.92 \%)$ and four years bachelor degree $(18.52 \%)$. The rest $5.56 \%$ and $3.7 \%$ of the respondents had double MS and post.-doctoral degree respectively (Table 5). Majority $(71.42 \%)$ of the professors had $\mathrm{PhD}$ degree, while half $(50 \%)$ of the Associate Professors had the same degree. Majority of the Assistant Professors (59.09\%) and Lecturer (52.94\%) had MS degree (Table 5).

The curriculum vitae of the respondents indicate that among the 54 respondent teachers most (50, i.e., $93 \%$ ) of the teachers have all through first class (from SSC to Masters Level). It indicates that the KU authority is sincere to select faculty members for better academic attainment.

\section{Training Experience}

Training experience scores of the respondents ranged from 0 to 8 with an average of 2.94 and standard deviation of 2.17 . Depending on the number of training received, the respondents were grouped into the following four categories as shown Table 6. About half $(48 \%)$ of the respondents had low training experience whereas more than one-fourths $(28 \%)$ of the respondents had medium training and about one-tenth (9\%) had high training experience. The rest $15 \%$ did not received any training on the selected areas (Table 6).

Findings of Table 7 indicate that majority $(57.41 \%)$ of the respondents received training on research methodology followed by teaching methodology $(38.89 \%)$, computer skill (29.63\%), extension and outreach $(22.22 \%)$ and office management and administration (18.52\%). Some of the respondent teachers took training more than one time on teaching methodology and research methodology. There were 14 respondent teachers who did not receive any training in any of these areas.

\section{Level of knowledge and nature of training need}

\section{Level of knowledge}

The overall level of knowledge scores of the respondents ranged from 38 to 97 with an average of 69.11 and standard deviation of 12.94. Depending on the level of knowledge scores, the respondents were grouped into the following five categories as shown in the Table 8.

Most of the respondents (77\%) had substantial to high knowledge whereas about one-fifth $(17 \%)$ of the respondents had very high knowledge. The rest $6 \%$ had some knowledge on the selected issues of training. None had little knowledge (Table 8).

\section{Nature of Training Need}

The overall training need scores of the respondents ranged from 24 to 100 with an average of 66.28 and standard deviation of 21.03. Depending on the training need scores, the respondents were grouped into the following five categories as shown in the Table 9.

Highest proportion $(35 \%)$ of the respondents showed urgent need followed by substantial $(22 \%)$ and very urgent need (19\%) for training on the selected issues. About one fifth (19\%) of the respondents indicated some need while only onetwentieth $(5 \%)$ of the respondents expressed little need for raining (Table 9). This might be due to that the respondents consisted of about one-fourth (24\%) with highly experienced teachers (Table 4). Though all the respondents possessed some to very high knowledge but they expressed little to very urgent need of training. It is usually assumed that the higher is the knowledge on the issue; the lower is the training need. The reason behind expressing little to very urgent training need provided with some to very high knowledge might be that the respondents want to refresh and/or update their knowledge on the selected issues.

\section{Identification of areas of Knowledge and Training}

The knowledge index and training need index were calculated to identify the areas and issues on which they have high knowledge as well as to identify important areas and issues on which they want to take training. The findings of knowledge index and training need index are presented in Table 10.

Results of Table 10 indicate that the respondents possessed highest level of knowledge on teaching methodology, while it was least on extension and outreach. It is assumed that the higher is the knowledge; the lower is the training need. This assumption is proved in case of this study. Because the respondents had expressed little urgency of training need in case of teaching methodology and very urgency of training need in extension and outreach. Besides, the respondent teachers identified issues of training based on their priorities. The top five issues under different broad areas on which they want to take training are conflict management (under extension and outreach), budget preparation (office management and administration), acquaintance with field problem (extension and outreach), research design and project preparation (research methodology), and data analysis and management (computer skill).

\section{Relationship between the selected characteristics of the respondents and their training needs}

The purpose of this section is to examine and describe the relationship between the training needs (focus variable) and the selected characteristics of the respondents. To explore the relationship between the selected characteristics of the teachers and their training needs, "Pearson's Product-Moment Correlation Co-efficient ' $r$ ' was used which has been shown in the Table 11. 
Table 7. Distribution of the respondents according to their training experience (according to areas)

\begin{tabular}{lcc}
\hline Areas of Training & \multicolumn{2}{c}{ Respondents (N=54)** } \\
\cline { 2 - 3 } & Number & Percentage \\
\hline Teaching Methodology & 21 & 38.89 \\
\hline Research Methodology & 31 & 57.41 \\
\hline Computer Skill & 16 & 29.63 \\
\hline Office management and Administration & 10 & 18.52 \\
\hline Extension \& Outreach & 12 & 22.22 \\
\hline
\end{tabular}

** Multiple answers questions

Table 8. Distribution of the respondents according to their level of knowledge

\begin{tabular}{|c|c|c|c|c|c|}
\hline \multirow[t]{2}{*}{ Categories } & \multirow[t]{2}{*}{ Score } & \multicolumn{2}{|c|}{ Respondents $(\mathrm{N}=54)$} & \multirow[t]{2}{*}{ Mean } & \multirow{2}{*}{$\begin{array}{l}\text { Standard } \\
\text { deviation }\end{array}$} \\
\hline & & Number & Percent & & \\
\hline Little knowledge & Up to $3 o$ & 00 & 00 & 69.11 & 12.94 \\
\hline Some knowledge & $31-50$ & 03 & 06 & & \\
\hline Substantial knowledge & $51-70$ & 25 & 46 & & \\
\hline High knowledge & $71-90$ & 17 & 31 & & \\
\hline Very high knowledge & $>90$ & 09 & 17 & & \\
\hline Total & & 54 & 100 & Min.38 & Max.97 \\
\hline
\end{tabular}

Table 9. Distribution of the respondents according to their training need

\begin{tabular}{|c|c|c|c|c|c|}
\hline \multirow[t]{2}{*}{ Categories } & \multirow[t]{2}{*}{ Score } & \multicolumn{2}{|c|}{ Respondents $(\mathrm{N}=54)$} & \multirow[t]{2}{*}{ Mean } & \multirow{2}{*}{$\begin{array}{l}\text { Standard } \\
\text { deviation }\end{array}$} \\
\hline & & Number & Percent & & \\
\hline Little need & Up to 30 & 03 & 05 & 66.28 & 21.03 \\
\hline Some need & $31-50$ & 10 & 19 & & \\
\hline Substantial need & $51-70$ & 12 & 22 & & \\
\hline Urgent need & $71-90$ & 19 & 35 & & \\
\hline Very Urgent need & $>90$ & 10 & 19 & & \\
\hline Total & & 54 & 100 & Min.24 & Max.100 \\
\hline
\end{tabular}

Table 10. Rank order of selected areas and items based on KI and TNI

\begin{tabular}{|c|c|c|c|c|c|}
\hline \multirow[t]{2}{*}{$\begin{array}{l}\text { Sl. } \\
\text { No. }\end{array}$} & \multirow[t]{2}{*}{ Sub areas and items (issues) of training } & \multicolumn{2}{|c|}{ Knowledge Index (KI) } & \multicolumn{2}{|c|}{$\begin{array}{l}\text { Training Need Index } \\
\text { (TNI) }\end{array}$} \\
\hline & & Score & Rank & Score & Rank \\
\hline $\mathbf{A}$ & A. Teaching Methodologies & 785 & $\mathbf{1}^{\text {st }}$ & 656 & $5^{\text {th }}$ \\
\hline 1 & A.1 Specific subject matter & 206 & $2^{\text {nd }}$ & 152 & $18^{\text {th }}$ \\
\hline 2 & A.2 Use of audio-visual aids & 191 & $6^{\text {th }}$ & 156 & $17^{\text {th }}$ \\
\hline 3 & A.3 Deliberation technique & 186 & $9^{\text {th }}$ & 173 & $12^{\text {th }}$ \\
\hline 4 & A.4 Class management & 202 & $3^{\text {rd }}$ & 175 & $11^{\text {th }}$ \\
\hline $\mathbf{B}$ & B. Research Methodology & 755 & $2^{\text {nd }}$ & 743 & $2^{\text {nd }}$ \\
\hline 5 & B.1 Identification of research problems & 190 & $7^{\text {th }}$ & 188 & $7^{\text {th }}$ \\
\hline 6 & B.2 Research design \& project preparation & 176 & $14^{\text {th }}$ & 196 & $4^{\text {th }}$ \\
\hline 7 & B.3 Data analysis and interpretation & 193 & $5^{\text {th }}$ & 187 & $8^{\text {th }}$ \\
\hline 8 & B.4 Technical report writing/ reviewing & 196 & $4^{\text {th }}$ & 172 & $13^{\text {th }}$ \\
\hline $\mathbf{C}$ & C. Computer Skill & 693 & $4^{\text {th }}$ & 716 & $4^{\text {th }}$ \\
\hline 9 & C.1 Office application & 210 & $1^{\text {st }}$ & 173 & $12^{\text {th }}$ \\
\hline 10 & C.2 Language programming & 136 & $19^{\text {th }}$ & 179 & $10^{\text {th }}$ \\
\hline 11 & C.3 Software & 165 & $15^{\text {th }}$ & 170 & $15^{\text {th }}$ \\
\hline 12 & C.4 Data analysis/ management & 182 & $12^{\text {th }}$ & 194 & $5^{\text {th }}$ \\
\hline $\bar{D}$ & D. Office management and Administration & 711 & $3^{\text {rd }}$ & 720 & $3^{\text {rd }}$ \\
\hline 13 & D.1 Job Description (Duties and responsibilities) & 185 & $10^{\text {th }}$ & 169 & $16^{\text {th }}$ \\
\hline 14 & D.2 Decision making/ Leadership & 189 & $8^{\text {th }}$ & 175 & $11^{\text {th }}$ \\
\hline 15 & D.3: Communication skill/ Human leadership & 180 & $13^{\text {th }}$ & 171 & $14^{\text {th }}$ \\
\hline 16 & D.4: Budget preparation/Financial management & 157 & $17^{\text {th }}$ & 205 & $2^{\text {nd }}$ \\
\hline $\mathbf{E}$ & E. Extension and Outreach & 665 & $5^{\text {th }}$ & 785 & $\mathbf{1}^{\text {st }}$ \\
\hline 17 & E.1 Acquaintance with recent research findings & 183 & $11^{\text {th }}$ & 186 & $9^{\text {th }}$ \\
\hline 18 & E.2 Acquaintance with field problems & 180 & $13^{\text {th }}$ & 198 & $3^{\text {rd }}$ \\
\hline 19 & E.3 Familiarities with objectives \& approaches of different extension organization & 142 & $18^{\text {th }}$ & 191 & $6^{\text {th }}$ \\
\hline 20 & E.4 Conflict management & 160 & $16^{\text {th }}$ & 210 & $1^{\text {st }}$ \\
\hline
\end{tabular}


Table 11. Relationship between the selected characteristics of the respondents and their training needs

\begin{tabular}{|c|c|c|c|}
\hline $\begin{array}{l}\text { Sl. } \\
\text { No. }\end{array}$ & Selected characteristics of the respondents teachers & Focus issue/variable & r-value \\
\hline 1. & Age & Training needs & -0.058 \\
\hline 2. & Present position in $\mathrm{KU}$ & & -0.135 \\
\hline 3. & Professional experience & & -0.187 \\
\hline 4. & Educational qualification & & -0.175 \\
\hline 5. & Training experience & & -0.021 \\
\hline 6. & Level of knowledge & & $-0.272 *$ \\
\hline
\end{tabular}

* Significant at 0.05 level

Among the six selected characteristics of the respondent teachers only level of knowledge showed a negative significant relationship with their training needs. It means that the lower is the level of knowledge the higher is the training need. The rest selected characteristics showed no significant relationship with training needs of the respondents.

\section{CONCLUSION}

The teachers of Khulna University are mostly young. Majority of them are Lecturer and Assistant Professor, mostly low to medium professional experience, academically highly qualified, possessed low to medium training experience. They have high knowledge in teaching methods, but lowest level of knowledge in extension and outreach programs. They expressed highest training need in extension and outreach program. They also expressed their high training needs regarding conflict management under extension and outreach, budget preparation (office management and administration), acquaintance with field problem (extension and outreach), research design and project preparation (research methodology), and data analysis and management (computer skill). Among the selected personal characteristics, only level of knowledge showed a negative significant relationship with the training need of the respondents. The Khulna University authority should take initiative to train the teachers especially newly recruited teachers on the issues and areas identified by this study.

\section{ACKNOWLEDGEMENT}

The Authors are highly grateful to University Grants Commission (UGC) of Bangladesh for selection of the project and issuing research grants to conduct the study.

\section{REFERENCES}

Jucions, M.J. 1963. Personal Management (5 $5^{\text {th }}$ edition). Homewood. IL: Richard D. Irwin.

Malone, V.M. 1984. In-service training and staff development. In: B.F. Swanson (Ed.) Agricultural Extension: A Reference Manual- FAO, Rome.

Rogers, F.E. and Olmsted, A.G. 1957. Supervision in the Cooperative Extension Service. Madison, WI: National Agricultural Extension Center for Advanced Study.

Van Darsal, W.R. 1962. The Successful Supervisor. New York: Harper and Row. 